\title{
The importance of dietary composition for efficacy of iron absorption measured in a whole diet that includes rye bread fortified with ferrous fumerate: a radioisotope study in young women
}

\author{
Inge Tetens ${ }^{1}$, Tanja M. Larsen ${ }^{1}$, Mette Bach Kristensen ${ }^{1}$, Ole Hels ${ }^{1}$, Mikael Jensen ${ }^{2,3}$, Cathrine M. Morberg ${ }^{1}$, \\ Agnete D. Thomsen ${ }^{4}$, Liselotte Højgaard ${ }^{5}$ and Marianne Henriksen ${ }^{1} \dagger$ \\ ${ }^{1}$ Department of Human Nutrition/LMC Centre for Advanced Food Studies, The Royal Veterinary and Agricultural University, DK-1958 \\ Frederiksberg C, Denmark \\ ${ }^{2}$ Institute of Natural Sciences The Royal Veterinary and Agricultural University, DK-1958 Frederiksberg C, Denmark \\ ${ }^{3}$ Ris $\phi$ National Laboratory, DK-4000 Roskilde, Denmark \\ ${ }^{4}$ Cerealia, Schulstad Bread A/S, DK-2650 Hvidovre, Denmark \\ ${ }^{5}$ Department of Clinical Physiology and Nuclear Medicine, Rigshospitalet, Copenhagen University Hospital, DK-2100 Copenhagen, \\ Denmark
}

(Received 6 January 2005 - Revised 14 June 2005 - Accepted 20 June 2005)

\begin{abstract}
Fe absorption is affected by many dietary factors. The objective of the present study was to measure the effects of high $v$. low content of vitamin $\mathrm{C}$, meat and phytic acid in whole diets with Fe-fortified bread on the efficacy of Fe absorption. Thirty-two healthy women with low Fe stores were randomised to three groups, each of which was given two of six test diets containing either low/high amounts of vitamin C, meat or phytic acid, respectively, in a cross-over design. Each diet was served throughout a $5 \mathrm{~d}$ period. Fe-fortified rye bread, extrinsically labelled with ${ }^{59} \mathrm{Fe}$, was given with all main meals. Fe absorption was determined from whole-body counter measurements of ${ }^{59} \mathrm{Fe}$ retention. The fractional non-haem Fe absorption (corrected to a $40 \%$ standard absorption by measurements from the reference dose) was $1.9 \%$ v. $3.4 \%(P=0.04)$ for the low/high vitamin $\mathrm{C}$ diets, $3.0 \% \mathrm{v} .3 .5 \%(P=0.58)$ on the low/high meat diets and $4.9 \%$ v. $3.8 \%(P=0.24)$ on the low/high phytic acid diet, respectively. The total Fe absorbed (geometric mean with standard error) varied from 0.43 (SE 0.11 ) $\mathrm{mg}$ from the diet with lowest bioavailability to 1.09 (SE 0.18 ) $\mathrm{mg}$ from the diet with highest bioavailability $(P<0.001$ ). The present whole-diet study indicates that diet composition is a strong predictor of Fe absorption. In the diet with a low content of enhancers and a high content of inhibitors, vitamin $\mathrm{C}$ improved non-haem Fe absorption. The total Fe absorption varied $2 \cdot 5$-fold after small alterations of the content of enhancers and inhibitors in the diet.
\end{abstract}

Iron deficiency: Iron fortification: Vitamin C: Meat: Phytic acid

Fe deficiency and its anaemia (iron-deficiency anaemia) are common micronutrient deficiencies in both low-income and industrialised countries (Administrative Committee on Coordination/ Sub-Committee on Nutrition, 2000). Fe deficiency may arise from inadequate intakes of dietary Fe, poor absorption, excessive loss, or a combination of two or more of these. The amount of Fe absorbed from the diet is influenced by several factors, with the most influential being the Fe status of the individual (Reddy et al. 2000) but the Fe bioavailability of the diet plays a significant role (Wienk et al. 1999; Reddy et al. 2000; Heath \& Fairweather-Tait, 2002). The inhibiting effect of phytic acid (Hallberg et al. 1987; Brune et al. 1992) and polyphenols (Hallberg \& Rossander, 1982; Morck et al. 1983; Samman et al. 2001), and the enhancing effect of vitamin C (Hallberg et al. 1986, 1989), on the absorption of non-haem Fe are well established, whereas findings of the possible inhibiting effect of a concomitant intake of $\mathrm{Ca}$ are equivocal (Lynch, 2000).
Food fortification has long been considered an effective strategy for the prevention of iron-deficiency anaemia, but the longterm benefits of $\mathrm{Fe}$ fortification have not been established. The potential efficiency of dietary fortification depends on a number of factors, including the Fe status of the target group, total Fe intake, selection of food vehicle, the bioavailability of the $\mathrm{Fe}$, and the balance of inhibitors and enhancers of $\mathrm{Fe}$ absorption. A potential strategy to reduce a high prevalence of Fe deficiency is through fortification of food components often consumed by the target population (Hurrell, 2002). Rye bread, which is consumed on a daily basis in some of the Scandinavian countries, is a suitable vehicle for Fe fortification due to its dark colour and low risk of organoleptic deterioration caused by pro-oxidative properties (Hansen et al. 2005).

Studies have found a difference between Fe absorption from single-meal and from whole diets, indicating that the results

\footnotetext{
* Corresponding author: Dr Inge Tetens, Department of Nutrition, The Danish Institute for Food and Veterinary Research, Mørkhøj Bygade 19, DK-2860 Søborg, Denmark, fax +4572347119 , email intet@dfvf.dk
}

$\dagger$ Present address: Nycomed A/S, Roskilde, Denmark. 
from single-meal studies overestimate the effects on enhancers and inhibitors in the diet on $\mathrm{Fe}$ absorption (Cook et al. 1991), and that short-term measurements of absorption overestimate differences in Fe bioavailability (Hunt \& Roughead, 2000).

The aim of the present study was to measure the effects of high or low vitamin $\mathrm{C}$, meat and phytic acid content in a whole diet over five consecutive days on the efficacy of $\mathrm{Fe}$ absorption from a diet with $\mathrm{Fe}$-fortified rye bread. Cereal flours are currently the most common vehicles for Fe fortification, and rye bread is the major bread source in Denmark, where the study was conducted.

\section{Materials and methods}

Subjects

Thirty-two women, aged 21-29 years, with a BMI of $22.4 \pm 2.3 \mathrm{~kg} / \mathrm{m}^{2}$, participated in the study. All subjects had low serum ferritin stores (between 12 and $30 \mu \mathrm{g} / \mathrm{l}$ ) but were non-anaemic $(\mathrm{Hb}>110 \mathrm{~g} / \mathrm{l})$. The subjects were all apparently healthy, non-pregnant/lactating, non-smokers, and none of them took any vitamin or mineral supplements 2 months before or during the study. None used medicine regularly and $53 \%$ took oral contraceptives. None of the subjects donated blood within 2 months prior to or during the study. The subjects were given written and oral information about the study and written consent was obtained from all subjects. The study was approved by the Municipal Ethical Committee of Copenhagen and Frederiksberg (KF 01-100/97) and the National Institute of Radiation Hygiene, Denmark.

\section{Experimental design}

The subjects were randomised to participate in one of three completely controlled dietary cross-over arms of the study in which the effects of low/high vitamin $\mathrm{C}$ content (study $\mathrm{A}$, diets $\mathrm{A} 1$ and A2), low/high meat content (study B, diets B1 and B2) and low/high phytic acid content (study $\mathrm{C}$, diets $\mathrm{C} 1$ and $\mathrm{C} 2$ ) on $\mathrm{Fe}$ bioavailability were investigated (Table 1). In studies A and B the effect of a promoting factor was investigated and the diet was designed to have a high content of inhibitory factors and a low content of other enhancers. In study $\mathrm{C}$ the effects of an inhibitor was investigated and the diet had a high content of promoting factors and a low content of other inhibitors. Each study consisted of two $5 \mathrm{~d}$ intervention periods during which $\mathrm{Fe}$-fortified rye bread extrinsically labelled with ${ }^{59} \mathrm{Fe}$ was given with all main meals. Fe absorption was calculated from whole-body counting measurements performed $14 \mathrm{~d}$ after the last day of each $5 \mathrm{~d}$ period. With this design the whole-body counting measurements served as baseline for the following intervention period. After the second dietary $5 \mathrm{~d}$ period a ${ }^{59} \mathrm{Fe}$-labelled iron chloride oral reference dose solution was given without any accompanying meal, and absorption of this dose was determined by whole-body counting another 2 weeks later.

\section{Iron-fortified rye bread}

The rye bread consisted of water, rye flour, rye grains, sourdough, breadcrumbs, dark syrup, salt, vinegar and yeast. Ferrous fumarate (Sigma, St Louis, MO, USA) was added to the dough before baking, corresponding to $6 \mathrm{mg} F e$ per $100 \mathrm{~g}$ bread. The bread was prepared and baked by a commercial bakery (Schulstad Bread A/S, 2650 Hvidovre, Denmark) with experience in baking with fortification.

\section{Composition of test meals and serving procedure}

Each subject was assigned to an energy intake based on individual energy requirements estimated from body weight and physical activity level. Apart from different contents of vitamin C, meat and phytic acid (Table 1), the diets had either a relatively high (diets A1 and A2) or relatively low (diets $\mathrm{C} 1$ and $\mathrm{C} 2$ ) $\mathrm{Ca}$ content and were served either with (diets A1, A2, B1, B2) or without (diets $\mathrm{C} 1$ and $\mathrm{C} 2$ ) tea. A 1 day menu was repeated for all $5 \mathrm{~d}$ in each diet period. The serving order of the two diet types was randomised. The menu consisted of typical Danish food items (Table 2) and the dietary factors mentioned earlier were equally distributed between the main meals. Diets A1, A2 and B1 had a low content of meat (given as pork Longissimus dorsi) with 0 $10 \mathrm{~g}$ at breakfast and $15-25 \mathrm{~g}$ at lunch and dinner, per $10 \mathrm{MJ} / \mathrm{d}$. Diets B2, C1 and C2 had a high content of pork meat $(150 \mathrm{~g} / \mathrm{d})$ with $30 \mathrm{~g}$ eaten at breakfast, $45 \mathrm{~g}$ at lunch and $75 \mathrm{~g}$ at dinner, per $10 \mathrm{MJ} / \mathrm{d}$. Each subject was given $120 \mathrm{~g}$ rye bread/d per $10 \mathrm{MJ}$, which was evenly distributed over the three main meals. $\mathrm{Ca}$ and $\mathrm{Fe}$ content were matched in order to compare the diets both pair-wise in each study group and in all six diets.

All main meals were consumed at the Department of Human Nutrition under supervision within fixed time limits (breakfast at $07.30-08.30$ hours, lunch at 12.00-13.00 hours and dinner at 17.00-18.30 hours). A snack meal consisting of a white wheat roll with jam was consumed at home each evening (minimum $3 \mathrm{~h}$ after dinner). The meals were separated by more than $3 \mathrm{~h}$ $30 \mathrm{~min}$ and the subjects fasted for $12 \mathrm{~h}$ before receiving the first meal of the $5 \mathrm{~d}$ period. The meals were served on disposable material and the subjects were instructed to consume the meal within $30 \mathrm{~min}$ and to alternate between eating and drinking. Mineral water, low in Ca and without any EDTA or other ingredients known to affect $\mathrm{Fe}$ absorption, was given ad libitum and the

Table 1. Study design*

\begin{tabular}{|c|c|c|c|c|c|}
\hline \multicolumn{2}{|c|}{ Study A } & \multicolumn{2}{|c|}{ Study B } & \multicolumn{2}{|c|}{ Study C } \\
\hline Diet A1 & Diet A2 & Diet B1 & Diet B2 & Diet C1 & Diet C2 \\
\hline Low vitamin C & High vitamin $C$ & Low vitamin C & Low vitamin $C$ & High vitamin $\mathrm{C}$ & High vitamin $\mathrm{C}$ \\
\hline Low meat & Low meat & Low meat & High meat & High meat & High meat \\
\hline High phytic acid & High phytic acid & High phytic acid & High phytic acid & Low phytic acid & High phytic acid \\
\hline
\end{tabular}


Table 2. Menus for the six test diets with either high or low contents of vitamin C, meat and phytic acid

\begin{tabular}{|c|c|c|c|c|c|c|}
\hline & Diet A1 & Diet A2 & Diet B1 & Diet B2 & Diet C1 & Diet C2 \\
\hline \multirow[t]{8}{*}{ Breakfast } & Tea & Tea & Tea & Tea & Orange juice & Orange juice \\
\hline & Oatmeal & Orange juice & Oatmeal & Oatmeal & Yoghurt & Oatmeal \\
\hline & Milk & Milk & Milk & Milk & Rye bread & Sugar \\
\hline & Rye bread & Rye bread & Rye bread & Rye bread & White wheat roll & Rye bread \\
\hline & Sugar & Sugar & Sugar & Sugar & Butter & Butter \\
\hline & Water & Cheese & Cheese & Cheese & Meat (pork) & Meat (pork) \\
\hline & & Water & Meat (pork) & Meat (pork) & Liver paste & Cod roe \\
\hline & & & Water & Water & Water & Water \\
\hline \multirow[t]{11}{*}{ Lunch } & Tea & Tea & Tea & Tea & Orange juice & Orange juice \\
\hline & Milk & Milk & Milk & Milk & Rye bread & Rye bread \\
\hline & Rye bread & Rye bread & Rye bread & Rye bread & White wheat roll & Whole wheat bread \\
\hline & Whole wheat bread & Whole wheat bread & Whole wheat bread & Whole wheat bread & Meatball & Meatball \\
\hline & Meatball & Meatball & Meatball & Meatball & Carrots & Mayonnaise \\
\hline & Egg & Egg & Egg & Egg & Raisins & Peas \\
\hline & Mayonnaise & Mayonnaise & Mayonnaise & Mayonnaise & Liver paste & Carrots \\
\hline & Lettuce & Lettuce & Peas & Peas & Butter & Cod roe \\
\hline & Carrots & Carrots & Sugar & Sugar & Water & Water \\
\hline & Sugar & Orange juice & Cod roe & Orange & & \\
\hline & Water & Water & $\begin{array}{l}\text { Orange } \\
\text { Water }\end{array}$ & Water & & \\
\hline \multirow[t]{6}{*}{ Dinner } & Chilli con carne & Chilli con carne & Chilli con carne & Chilli con carne & Chilli con carne & Chilli con carne \\
\hline & Rye bread & Rye bread & Rye bread & Rye bread & Rye bread & Rye bread \\
\hline & Tea & Tea & Tea & Tea & Sponge cake & Chocolate \\
\hline & Chocolate & Chocolate & Cheese & Chocolate & Orange juice & Orange juice \\
\hline & Sugar & Orange juice & Chocolate & Sugar & Liver paste & Water \\
\hline & Water & Water & $\begin{array}{l}\text { Sugar } \\
\text { Water }\end{array}$ & Water & Water & \\
\hline Snack & $\begin{array}{l}\text { White wheat roll } \\
\text { Jam }\end{array}$ & $\begin{array}{l}\text { White wheat roll } \\
\text { Jam }\end{array}$ & $\begin{array}{l}\text { White wheat roll } \\
\text { Jam }\end{array}$ & $\begin{array}{l}\text { White wheat roll } \\
\text { Jam }\end{array}$ & $\begin{array}{l}\text { White wheat roll } \\
\text { Jam }\end{array}$ & $\begin{array}{l}\text { White wheat roll } \\
\text { Jam }\end{array}$ \\
\hline
\end{tabular}

amount consumed was recorded during the first study period. Each individual was instructed to drink the same amount of water on the corresponding days of the second dietary period. Macronutrient values and contents of vitamin $\mathrm{C}$ were calculated using the Dankost ${ }^{\circledR}$ dietary assessment software, accounting for the fortification of the bread (Danish Catering Center, Herlev, Denmark). Duplicate portions from each dietary intervention were collected in acid-washed polyethylene containers for chemical analyses of $\mathrm{Fe}, \mathrm{Ca}, \mathrm{N}$ and phytic acid.

\section{Reference dose}

Each subject consumed a standard Fe reference dose after the whole-body counting at the conclusion of the second dietary period. The solution contained $3.0 \mathrm{mg}$ elemental $\mathrm{Fe}$ as ferrous sulphate (Merck, Darmstadt, Germany) (Hallberg \& Hultén, 1996) and $30 \mathrm{mg} \mathrm{L}-(+)$-ascorbic acid (Merck) in $0.01 \mathrm{~mol} / \mathrm{l} \mathrm{HCl}$. The reference dose was labelled with ${ }^{59} \mathrm{Fe}$ (as high specific activity chloride solution) given on two consecutive mornings. The solution was prepared and served in a plastic vial, which was subsequently rinsed twice in $50 \mathrm{ml}$ ultra-pure water, which was also consumed by the subjects. The subjects had fasted for $12 \mathrm{~h}$ prior to ingestion of the solution on both occasions and were asked not to consume any food or beverage for a further $3 \mathrm{~h}$. Whole-body counting was carried out $12-13 \mathrm{~d}$ later.

\section{Isotopes and labelling procedures}

Breakfast, lunch and dinner meals were extrinsically labelled with ${ }^{59} \mathrm{Fe}$ by drop-wise addition of isotope solution $(0.5-1.0 \mathrm{ml})$ to the rye bread. The radioisotope was purchased as ${ }^{59} \mathrm{Fe}$-labelled ferric chloride in $0.1 \mathrm{M}-\mathrm{HCl}$ (Amersham Pharmacia Biotech, Amersham, UK) at a specific activity of $150 \mathrm{GBq} / \mathrm{g}$ Fe. The activity and specific activity was standardised by dilution with $0.1 \mathrm{M}-\mathrm{HCl}$ and addition of stable ferric chloride to $3.6 \mathrm{kBq} / \mathrm{ml}$ and $0.625 \mathrm{GBq} / \mathrm{g} \mathrm{Fe}$ at time of administration. In each dietary period a dose of $8 \mathrm{kBq} / \mathrm{d}$, i.e. $40 \mathrm{kBq}$ per $5 \mathrm{~d}$ period, was distributed over the meals in relation to the $\mathrm{Fe}$ content in order to obtain equal specific radioactivity in the meals. Each of the two reference doses was labelled with $20 \mathrm{kBq}{ }^{59} \mathrm{Fe}$ each time, i.e. a total of $40 \mathrm{kBq}$. The extrinsic food labelling was undertaken approximately $16 \mathrm{~h}$ before serving. The estimated total activity of ${ }^{59} \mathrm{Fe}$ given to each subject was $120 \mathrm{kBq}$, which corresponds to calculated committed radiation dose of $0.288 \mathrm{mSv}$ to each subject (International Commission on Radiological Protection, 1988).

\section{Determination of iron absorption}

Fe absorption was estimated by measurement of ${ }^{59} \mathrm{Fe}$ whole-body retention in a whole-body counter $12-13 \mathrm{~d}$ after termination of each dietary period, and after the reference dose. This time period was chosen to allow for the excretion of non-absorbed isotopes. The whole-body counter, located at Rigshospitalet, Copenhagen University Hospital, Denmark, consists of a low-activity lead-lined steel chamber with four plastic scintillation blocks (NE110; Nuclear Enterprises Ltd, Edinburgh, UK), two placed above and two below the subject. The counting efficiency and window settings were established through measurements of water-filled phantoms with known concentrations of ${ }^{59} \mathrm{Fe}$ and outlines and weights approximately equal to human subjects. The window setting was optimised prior to the experiment to cover the entire compton spectrum from ${ }^{59} \mathrm{Fe}$ down to a practical 
lower limit of approximately $150 \mathrm{keV}$. The window setting was kept constant in between individuals and between phantom and subject measurements The counting efficiency for a $67 \mathrm{~kg}$ phantom was approximately 150,000 counts $/ 600 \mathrm{~s}$ per $\mathrm{kBq}{ }^{59} \mathrm{Fe}$, corresponding to an absolute detection efficiency of $25 \%$. In order to minimise influence from external contamination due to natural or manmade background activity, the subjects showered and washed their hair and were dressed in hospital clothing before each measurement. Each whole-body counting session lasted $10 \mathrm{~min}$. The results were corrected for chamber and individual subject background activity (mainly ${ }^{40} \mathrm{~K}$, as found from whole-body counter measurement before the start of the first test meal period) as well as for physical isotope decay.

\section{Calculation of non-haem and haem iron absorption}

Non-haem Fe absorption was corrected for the absorption from the reference dose to enable comparison between the three individual cross-over intervention studies. Based on $\mathrm{Fe}$ absorption from the reference dose, haem $\mathrm{Fe}$ absorption from each diet was estimated according to the following equation (Gleerup et al. 1995):

Haem Fe absorption $(\%)=$ absorption from reference dose $(\%)$

$$
\times 0 \cdot 322+15 \cdot 71 \text {. }
$$

\section{Dietary analyses}

Duplicate portions from each dietary period were homogenised (Tecator AD 1094; Tecator, Höganäs, Sweden), freeze dried (FD 8.0; Heto, Allerød, Denmark), ground to a powder, and analysed in duplicates for $\mathrm{Fe}, \mathrm{Ca}, \mathrm{N}$ and phytic acid content. Fe and $\mathrm{Ca}$ contents were analysed by atomic absorption spectrometry (Spectr-AA 200; Varian, Mulgrave, Victoria, Australia) after microwave destruction. Heat-treated meat (vacuum packed in plastic bags and heated in water at $70^{\circ} \mathrm{C}$ for $20 \mathrm{~min}$ ) was analysed separately for haem Fe content according to Carpenter \& Clark (1995). The absorbance of hemine was measured at $640 \mathrm{~nm}$ on a Lambda 15 spectrometer (Perkin-Elmer, Norwalk, CT, USA). N was analysed by GC after combustion (NA 1500 Carlo Erba; Fisions Instruments, Milan, Italy) using the Dumas method. Protein was calculated by multiplying measured $\mathrm{N}$ content by 6.25 . A reference material (Standard Reference Material 1548, total diet, National Institute of Standards and Technology, Gaithersburg, MD, USA) was analysed for $\mathrm{Fe}, \mathrm{Ca}$ and $\mathrm{N}$ in the same run as the diet samples (Fe: 35.3 (SE 3.8) $\mu \mathrm{g} / \mathrm{g}$, certified value: 33.0 (SE 3.9) $\mu \mathrm{g} / \mathrm{g}$; Ca: 1967 (SE 113) mg/kg, certified value: 2050 (SE 30) mg/kg; N: $29 \cdot 7$ (SE 1.6) $\mathrm{mg} \mathrm{N} / \mathrm{g}$, certified value: 30.3 (SE 3.1) mg N/g). Phytic acid content was assessed as myoinositol hexaphosphate and its degradation products, myoinositol tri-, tetra- and pentaphosphates, by HPLC as described by Skoglund et al. (1998).

\section{Blood sampling and analysis}

Blood samples of $10 \mathrm{ml}$ were taken at screening and analysed for serum ferritin and $\mathrm{Hb}$ concentration. Samples were drawn after a $12 \mathrm{~h}$ fast (consumption of 0.5 litre of water was allowed) and $10 \mathrm{~min}$ of rest in the supine position. Subjects were asked to refrain from physical exercise for $36 \mathrm{~h}$ and alcohol/medication for $24 \mathrm{~h}$ before blood sampling. In order to prevent artificially high values of serum ferritin due to infections, subjects were carefully instructed to report any sign of infection at the time of blood sampling. In the case of infection blood samples were postponed until $14 \mathrm{~d}$ after the end of infection as judged by the subject.

For analysis of $\mathrm{Hb}, 4.5 \mathrm{ml}$ blood was collected in a vacutainer tube containing disodium EDTA $(0.01 \%)$. A separate blood sample $(5 \mathrm{ml})$ was collected into plain tubes for the determination of serum ferritin concentration. The samples were centrifuged at $3000 \mathrm{~g}$ for $15 \mathrm{~min}$ at room temperature within $1 \mathrm{~h}$ of collection and the serum withdrawn was stored at $-20^{\circ} \mathrm{C}$ until ferritin analysis. $\mathrm{Hb}$ was analysed within $4 \mathrm{~h}$ of collection.

Blood samples were analysed for $\mathrm{Hb}$ on a Sysmex KX-21 (Automated Hematology Analyser, Kobe, Japan). An internal control was included in all runs with intra-assay $\mathrm{CV}$ of $0.59 \%$ ( $n 5), 0.95 \%(n 10)$ and $2.2 \%(n 5)$. Serum ferritin was analysed by delayed fluorometry (Delfia Fluorometer 1235/514; Wallac Oy, Turku, Finland) with a kit adapted for the Delfia system (Delfia Ferritin Kit B069/101; Wallac Oy). The ferritin assay was calibrated against WHO ferritin 94/572 Third International Standard. The detection limit was $0.5 \mu \mathrm{g} / \mathrm{l}$, the intra-assay CV was $2.1 \%$ and the inter-assay $\mathrm{CV}$ was $5 \%$ for an internal control. $\alpha-1$ Anti-chymotrypsin in serum was analysed by turbidimetric detection of antigen-antisolid reaction on Cobas Miraplus (Roche Diagnostic Systems; F. Hoffmann-La Roche Ltd, Basel, Switzerland). The inter-assay CV was $2.8 \%$ for an internal control. A reference material (DAKO Human Serum Protein Low (0939) and High (0940); DAKO, Glostrup, Denmark) was analysed in the same run as the blood samples (low: $0.27 \mathrm{~g} / \mathrm{l}$, certified value: $0.21-0.29 \mathrm{~g} / \mathrm{l}$; high: $0.72 \mathrm{~g} / \mathrm{l}$, certified value: $0 \cdot 55-0.75 \mathrm{~g} / \mathrm{l})$.

\section{Statistical analysis}

The sample size was calculated from previous data collected at the Department on Fe absorption from single meals containing amounts of meat and phytic acid similar to those in the present study diets (Bæch et al. 2003). To obtain a power of $80 \%$ it was calculated that nine subjects were needed to detect a $1.5 \%$ change in $\mathrm{Fe}$ absorption at a significance level of 0.05 (Administrative Committee on Coordination/Sub-Committee on Nutrition, 2000). All analyses were performed using the Statistical Analysis System software package, version 8.2 (SAS Institute, Cary, NC, USA). Univariate mixed model ANOVA was performed in the procedure MIXED. In the statistical model, non-haem Fe corrected $(\%)$, non-haem $\mathrm{Fe}$ corrected $(\mathrm{mg})$ and total $\mathrm{Fe}(\mathrm{mg})$ were evaluated as the dependent variable, and diet (low/high amounts of vitamin $\mathrm{C}$, meat or phytic acid) was included as an independent fixed effect. The three studies (A, B and C) were regarded as blocks and were included both as independent main fixed effect and in interaction with diet. Subjects nested within a study were included as a random effect. Tukey's test was used for the post hoc detection of significant pairwise comparisons. Homogeneity of variance and normal distribution among random effects were investigated by plots of residuals. Shapiro-Wilk's test for normal distribution was performed. The investigations showed that it was necessary to log-transform values of non-haem Fe corrected (\%), non-haem $\mathrm{Fe}$ corrected $(\mathrm{mg})$ and total $\mathrm{Fe}(\mathrm{mg})$. Least square means and standard errors were estimated and transformed back where necessary before presentation. 


\section{Results}

All main meals were extrinsically labelled and consumed at the Department under supervision by a staff member. Compliance to the dietary intervention was evaluated as high. Subjects' initial mean body weight (64.6 (SD 7.7) $\mathrm{kg}$ was maintained to within $0.1 \%$ during the study. The screening mean $\mathrm{Hb}$ concentration was 123 (SE 0.89) g/l and the mean serum ferritin concentration was $20 \cdot 2$ (SE 1.4) $\mu \mathrm{g} / \mathrm{l}(95 \% \mathrm{CI} 16 \cdot 0,18 \cdot 0)$. Mean $\alpha-1$ anti-chymotrypsin concentration was 0.28 (SE $0 \cdot 01$ ) g/l (range $0 \cdot 17-0 \cdot 35$ ), indicating that concentration of serum ferritin was not increased due to infections.

The nutrient compositions of the diets, and content of potential inhibitors and enhancers of $\mathrm{Fe}$ absorption, are shown in Table 3. Mean energy intake for the subjects was 10.7 (SE 0.7) MJ/d. The total $\mathrm{Fe}$ content of the diets was similar, with an average nonhaem $\mathrm{Fe}$ content of $17.4 \mathrm{mg} / \mathrm{d}$ per $10 \mathrm{MJ}$. Fe fortification amounted on average to $7.3 \mathrm{mg}$ in a $10 \mathrm{MJ}$ diet, corresponding to $42 \%$ of the non-haem $\mathrm{Fe}$ content. The diet with a high phytic acid content contained 1248 (SE 19) $\mu \mathrm{mol} / 10 \mathrm{MJ}$ on average, while diet $\mathrm{C} 1$ with low phytic acid content contained almost four times less phytic acid $(543 \mu \mathrm{mol} / 10 \mathrm{MJ})$. In the low vitamin $\mathrm{C}$ diets (A1, B1 and $\mathrm{B} 2$ ), the contents ranged from 26 to $34 \mathrm{mg} /$ 10 MJ. In the high vitamin $\mathrm{C}$ diets (A2, C1 and $\mathrm{C} 2)$ the vitamin $\mathrm{C}$ content ranged from 115 to $123 \mathrm{mg} / 10 \mathrm{MJ}$. The Ca content was similar in the two test periods of each study. The macronutrient composition was similar in all six diets.

The fractional and absolute absorption of non-haem Fe, haem $\mathrm{Fe}$ and total $\mathrm{Fe}$ from the six diets is presented in Table 4. Fractional non-haem $\mathrm{Fe}$ absorption was $80 \%$ lower from diet A1 with low vitamin $\mathrm{C}$ content $(26 \mathrm{mg} / \mathrm{d})$ than from diet $\mathrm{A} 2$ with high vitamin $\mathrm{C}$ content $(115 \mathrm{mg} / \mathrm{d})(P=0.04)$, and total Fe absorption was significantly lower $(74 \%, P=0.02)$. No significant difference was found between fractional non-haem Fe absorption from diet B1 (low meat content) and B2 (high meat content) and no significant difference was found between fractional non-haem $\mathrm{Fe}$ absorption from diet $\mathrm{C} 1$ (low phytic acid content) and $\mathrm{C} 2$ (high phytic acid content).

For comparison of the Fe absorption values between the three groups, absorption was corrected for absorption from the reference dose. The lowest percentage (geometric mean) non-haem
Fe absorption was 1.9 (SE 0.5) from diet A1 and the highest percentage was from diet $\mathrm{C} 1$ with 4.9 (SE 0.9) $(P=0.007)$. Absorption of non-haem $\mathrm{Fe}$ was highest $(0.91(\mathrm{SE} 0.17) \mathrm{mg}$ ) from diet C1 containing $121 \mathrm{mg}$ vitamin $\mathrm{C}, 150 \mathrm{mg}$ meat and $543 \mu \mathrm{mol}$ phytic acid, and it was lowest (0.37 (SE 0.09) mg) from diet A1 containing $26 \mathrm{mg}$ vitamin $\mathrm{C}, 50 \mathrm{~g}$ meat and $1951 \mu \mathrm{mol}$ phytic acid $(P=0.011)$. Total $\mathrm{Fe}$ absorption was highest from the diets $\mathrm{C} 1$ and $\mathrm{C} 2$ (high vitamin $\mathrm{C}$ and meat content and a low or high phytic acid content, respectively) and lowest from the low bioavailability diet (A1), resulting in a 2.5 -fold increase in the absorption ratio between the most promoting diet $(\mathrm{C} 1)$ and the most inhibiting diet (A1) on non-haem $\mathrm{Fe}$ and total $\mathrm{Fe}$ absorption $(P<0 \cdot 001)$.

\section{Discussion}

The present study shows that the overall efficacy of Fe absorption from a diet of which $42 \%$ of total $\mathrm{Fe}$ was from Fe-fortified bread depends on the dietary composition of the total diet. Ascorbic acid improved Fe bioavailability in a meal with otherwise low bioavailability, in a diet with a low content of enhancers and a high content of inhibitors. Meat content was of less importance than vitamin $\mathrm{C}$ and phytic acid content for non-haem Fe absorption from a diet including Fe-fortified rye bread. Low phytic acid content and high vitamin $\mathrm{C}$ and meat content improved $\mathrm{Fe}$ absorption significantly compared to a meal with low bioavailability.

The design of the present study is ideal for studying the effects of enhancers and inhibitors on Fe absorption from the diet. Effects of intake of vitamin $\mathrm{C}$, meat and phytic acid on the absorption of Fe are investigated separately in individual cross-over intervention studies, and the enhancing and inhibiting effects are compared in the three cross-over studies. The subjects consumed the high or low vitamin $\mathrm{C}$ diet, the high or low meat diet, or the high or low phytic acid diet, in a randomised design minimising the effects of naturally occurring biological variations. Apart from the Fe fortification of the rye bread and the total amount of rye bread that was double the amount of rye bread usually consumed by Danish women, the diets of the present study reflect diets that are normally consumed in Denmark.

An increase in the calculated daily intake of ascorbic acid from 26 to $115 \mathrm{mg}$ in the whole diet used in the present study increased

Table 3. Nutrient composition and content of potential inhibitors and promoters of iron absorption (per $10 \mathrm{MJ}$ )

\begin{tabular}{|c|c|c|c|c|c|c|}
\hline & Diet A1 & Diet A2 & Diet B1 & Diet B2 & Diet C1 & Diet C2 \\
\hline \multicolumn{7}{|l|}{ Inhibitors/promoters } \\
\hline Meat $(\mathrm{g})$ & 50 & 50 & 50 & 150 & 150 & 150 \\
\hline Vitamin C $(\mathrm{mg})^{*}$ & 26 & 115 & 34 & 30 & 121 & 123 \\
\hline Dietary fibre $(\mathrm{g})^{*}$ & 31 & 31 & 30 & 31 & 23 & 31 \\
\hline Phytic acid ( $\mu \mathrm{mol})$ & 1951 & 1951 & 1975 & 2002 & 543 & 2054 \\
\hline $\mathrm{Ca}(\mathrm{mg})$ & 979 & 1016 & 766 & 750 & 323 & 327 \\
\hline Tea/egg with meals & + & + & + & + & - & - \\
\hline \multicolumn{7}{|l|}{ Nutrient composition } \\
\hline Protein (g; E\%) & $82(14)$ & $83(14)$ & $84(14)$ & $90(15)$ & $81(14)$ & $88(15)$ \\
\hline Fat $(\mathrm{g} ; \mathrm{E} \%)^{*}$ & $82(31)$ & $82(31)$ & $85(32)$ & $81(30)$ & $81(31)$ & $82(31)$ \\
\hline Carbohydrate (g; E\%)* & $323(55)$ & $321(55)$ & $319(54)$ & $321(54)$ & $325(55)$ & $317(54)$ \\
\hline Total Fe (mg) & $18 \cdot 9$ & $20 \cdot 3$ & $20 \cdot 0$ & $21 \cdot 2$ & $21 \cdot 3$ & $22 \cdot 3$ \\
\hline Haem Fe (mg) & 0.17 & 0.17 & $0 \cdot 17$ & 0.5 & 0.5 & 0.5 \\
\hline Non-haem Fe (mg)† & $18 \cdot 7$ & $20 \cdot 1$ & $19 \cdot 8$ & $20 \cdot 7$ & $20 \cdot 8$ & $21 \cdot 8$ \\
\hline Phytic acid:Fe molar ratio & $5 \cdot 8: 1$ & $5 \cdot 4: 1$ & $5 \cdot 5: 1$ & $5 \cdot 1: 1$ & $1 \cdot 4: 1$ & $5 \cdot 2: 1$ \\
\hline
\end{tabular}

* Calculated from food composition tables (Dankost, Dankost Catering Centre, Herlev, DK (2002)).

†Calculated as the difference between total $\mathrm{Fe}$ and haem Fe content. 
Table 4. Fractional and absolute iron absorption*

\begin{tabular}{|c|c|c|c|c|c|c|c|c|c|c|c|c|}
\hline & \multicolumn{2}{|c|}{ Diet A1 } & \multicolumn{2}{|c|}{ Diet A2 } & \multicolumn{2}{|c|}{ Diet B1 } & \multicolumn{2}{|c|}{ Diet B2 } & \multicolumn{2}{|c|}{ Diet C1 } & \multicolumn{2}{|c|}{ Diet C2 } \\
\hline & Mean & SE & Mean & SE & Mean & SE & Mean & SE & Mean & SE & Mean & SE \\
\hline Non-haem Fe (\%) & 1.5 & $0.57^{\mathrm{b}}$ & $2 \cdot 7$ & $0.60^{\mathrm{a}}$ & $2 \cdot 9$ & 0.59 & 3.4 & 0.50 & 4.9 & 0.93 & 3.7 & 0.90 \\
\hline Reference dose (\%) & $36 \cdot 3$ & $6 \cdot 96$ & & & 43.5 & $5 \cdot 11$ & & & $40 \cdot 6$ & $2 \cdot 83$ & & \\
\hline Non-haem Fe corrected (\%)†‡ & 1.9 & $0.5^{\mathrm{b}}$ & $3 \cdot 4$ & $0.4^{\mathrm{ab}}$ & 3.0 & $0.6^{\mathrm{ab}}$ & 3.5 & $0.6^{\mathrm{ab}}$ & 4.9 & $0.9^{a}$ & 3.8 & $0.7^{\mathrm{ab}}$ \\
\hline Non-haem Fe corrected (mg)†‡ & 0.37 & $0.09^{b}$ & 0.69 & $0.08^{c}$ & 0.54 & $0 \cdot 10^{\mathrm{abc}}$ & 0.63 & $0.11^{\mathrm{abc}}$ & 0.91 & $0.17^{\mathrm{ac}}$ & $0 \cdot 76$ & $0 \cdot 15^{a b c}$ \\
\hline Haem Fe (\%) & $27 \cdot 4$ & $2 \cdot 2$ & & & $29 \cdot 7$ & 1.6 & & & $28 \cdot 8$ & 0.91 & & \\
\hline Haem Fe (mg) & 0.05 & 0.01 & & & 0.05 & 0.01 & 0.16 & 0.01 & $0 \cdot 15$ & 0.01 & & \\
\hline Total Fe $(\mathrm{mg}) \neq \S$ & 0.43 & $0.11^{d}$ & 0.75 & $0.13^{c}$ & 0.60 & $0.12^{\mathrm{abcd}}$ & 0.80 & $0.09^{\mathrm{abcd}}$ & 1.09 & $0.18^{a b c}$ & 0.92 & $0.19^{a b c}$ \\
\hline
\end{tabular}

${ }^{a, b, c, d}$ Mean values within a column with unlike superscript letters were significantly different $(P<0.05)$.

${ }^{*}$ For details of diets and procedures, see Tables 1-3 and p. 721.

† Geometric mean with standard error.

$\ddagger$ Individual absorption values corrected to $40 \%$ absorption from the reference dose.

$\S$ Non-haem Fe absorption corrected to the reference dose + haem Fe absorption estimated from the reference dose.

the absolute absorption of non-haem Fe from a meal with otherwise low bioavailability. The vitamin $\mathrm{C}$ content was evenly distributed between the three main meals and the increase in nonhaem $\mathrm{Fe}$ absorption is in accordance with findings from several single-meal studies showing improved Fe absorption when vitamin $\mathrm{C}$ was consumed in meals with high contents of phytic acid and polyphenols, the most potent inhibitors of Fe absorption (Hallberg et al. 1986, 1989; Siegenberg et al. 1991). Studies including a complete diet have shown a less pronounced effect of vitamin $\mathrm{C}$ on $\mathrm{Fe}$ absorption (Reddy et al. 2000; Cook \& Reddy, 2001) and one study has shown that long-term supplementation with vitamin $\mathrm{C}$ did not result in improved indexes of $\mathrm{Fe}$ status (Hunt et al. 1994). Whether results of $\mathrm{Fe}$ absorption obtained from single-meal studies can be compared to results obtained over longer periods has been debated intensively during the last decade (Cook et al. 1991; Hunt \& Roughead, 2000), but the reasons for the differences in results from singlemeal and long-term studies are still not clear.

Meat is a rich source of minerals and has a dual role in relation to daily Fe supply due to the high bioavailability of haem $\mathrm{Fe}$ in muscle tissue and the enhancing effect on the bioavailability of non-haem Fe (Layrisse et al. 1969; Martinez-Torres \& Layrisse 1971; Björn-Rasmussen \& Hallberg, 1979). The enhancing effect of meat on $\mathrm{Fe}$ availability is not understood and is usually referred to as the "meat factor". The "meat factor" may be related to the potential ability of sulphydryl-containing amino acids or peptides to chelate non-haem $\mathrm{Fe}$ and thereby facilitate intestinal absorption (Taylor et al. 1986; Bæch et al. 2003). Recently, it was suggested that carbohydrates originating from glycosaminoglycans in the extracellular matrix of muscle tissue is responsible for the enhancing effect on $\mathrm{Fe}$ availability (Huh et al. 2004).

In the present study, the meat content of the whole diet ranged from 50 to $150 \mathrm{~g} / 10 \mathrm{MJ}$ diet but no significant enhancement of non-haem Fe absorption was measured. From single-meal studies, Reddy et al. (2000) found highly positive correlations between animal tissue and non-haem Fe absorption and negative correlations between phytic acid and non-haem Fe absorption. In the present study, the daily portion of $150 \mathrm{~g}$ meat was consumed as $30 \mathrm{~g}$ at breakfast, $45 \mathrm{~g}$ at lunch and $75 \mathrm{~g}$ at dinner. A recent study has demonstrated that ingestion of $\geqq 50 \mathrm{~g}$ of pork meat significantly enhances non-haem $\mathrm{Fe}$ absorption in a dose-dependent manner from a diet with a high content of inhibitors and a low content of enhancers of Fe absorption (Bæch et al. 2003), but the study also showed that adding only $25 \mathrm{~g}$ meat to the meal caused no significant increase in fractional $\mathrm{Fe}$ absorption. It is therefore not surprising that no significant enhancing effect on non-haem $\mathrm{Fe}$ absorption was found in the present study.

Phytic acid is thought to be one of the strongest inhibitors of non-haem $\mathrm{Fe}$ absorption but the 4-fold higher phytic acid content of the whole diet in diet $\mathrm{C} 2$ compared to diet $\mathrm{C} 1$ caused no significant difference in non-haem $\mathrm{Fe}$ absorption when the dietary intake of phytic acid was evenly distributed between meals. Previous studies have shown that the quantitative inhibitory effect of phytic acid is similar over a wide range of phytic acid concentrations and is only reduced when there is very little phytic acid present (Hallberg et al. 1989). However, in the present study the content of phytic acid of all diets was relatively high (Table 3) mainly due to the rye bread. When calculating the phytic acid:Fe molar ratio of the diets (Table 3) they were all higher than the optimal ratio for Fe absorption which is $<1: 1$. This explains part of the relatively low Fe bioavailability of the present study. However, the high and low phytic acid diets had a relatively higher Fe bioavailability as they contained a high meat and vitamin $\mathrm{C}$ concentration and no intake of polyphenols from tea or coffee. The reason for a lack of difference between the high and low phytic acid diets on the Fe absorption could be the high intake of enhancers counteracting the effect of the high phytic acid content in diet $\mathrm{C} 2$.

Fractional $\mathrm{Fe}$ absorption from the low bioavailability diet of the present study (A1) was well in accordance with fractional Fe absorption found in a whole-diet study on young women by Hunt (2003). Fractional absorption from the high bioavailability diet was higher in the study by Hunt, as compared to the present study, most probably due to a lower phytic acid content and a higher vitamin C content in the diets in the study by Hunt (2003).

The results of the present study indicate that increased intake of vitamin $\mathrm{C}$ results in a relatively higher fractional $\mathrm{Fe}$ absorption from a diet with low bioavailability of $\mathrm{Fe}$ than do an increase in meat intake or a reduction in phytic acid intake. The relatively higher Fe bioavailability diet resulted in higher absorption of both fractional and total $\mathrm{Fe}$ as compared to the low bioavailability diet. The high bioavailability diet resulted in a $2 \cdot 5$-fold increased total Fe absorption. 


\section{Acknowledgements}

Financial support was provided by The Danish Food Technology Research Program for Food Technology (FØTEK). The authors want to thank the late Professor Brittmarie Sandström for initiating the study, Susanne Svalling, Department of Clinical Physiology and Nuclear Medicine, The National University Hospital, Copenhagen, Denmark and laboratory technician Hanne Lysdahl Pedersen, Department of Human Nutrition, The Royal Veterinary and Agricultural University, Frederiksberg, Denmark, for providing excellent technical assistance, and Tina Cuthbertson for help with language editing of the draft paper.

\section{References}

Administrative Committee on Coordination/Sub-Committee on Nutrition (2000) Fourth Report on the World Nutrition Situation, Nutrition Throughout the Life Cycle. Geneva: WHO, ACC, SCN and International Food Policy Research Institute.

Bæch SB, Hansen M, Bukhave K, Jensen M, Sørensen SS, Kristensen L, Purslow PP, Skibsted LH, Sandström B (2003) Nonheme iron absorption from a phytate-rich meal is increased by the addition of small amounts of pork meat. Am J Clin Nutr 77, 173-179.

Björn-Rasmussen E \& Hallberg L (1979) Effects of animal proteins in the absorption of food iron in man. Nutrition and Metabolism 23, 192-202.

Brune M, Rossander-Hultén L, Hallberg L, Gleerup A \& Sandberg A (1992) Iron absorption from bread in humans: inhibiting effects of cereal fiber, phytate and inositol phosphates with different numbers of phosphate groups. J Nutr 122, 442-449.

Carpenter CE \& Clark E (1995) Evaluation of methods used in meat iron analysis and iron content of raw and cooked meats. J Agric Food Chem 43, $1824-1827$.

Cook JD, Dassenko SA \& Lynch SR (1991) Assessment of the role of nonheme iron availability in iron balance. Am J Clin Nutr 54, 717-722.

Cook JD \& Reddy MB (2001) Effect of ascorbic acid intake on nonheme iron absorption from a complete diet. Am J Clin Nutr 73, 93-98.

Gleerup A, Rossander HL, Gramatkovski E \& Hallberg L (1995) Iron absorption from the whole diet: comparison of the effect of two different distributions of daily calcium intake. Am J Clin Nutr 61, 97-104.

Hallberg L, Brune M \& Rossander L (1986) Effect of ascorbic acid on iron absorption from different types of meals. Studies with ascorbicacid-rich foods and synthetic ascorbic acid given in different amounts with different meals. Hum Nutr Appl Nutr 40, 97-113.

Hallberg L, Brune M \& Rossander L (1989) Iron absorption in man: ascorbic acid and dose-dependent inhibition by phytate. Am J Clin Nutr 49, 140-144.

Hallberg L \& Hultén L (1996) Methods to study dietary iron absorption in man - an overview. In Iron Nutrition in Health and Disease, pp. 81-95 [L Hallberg and N-G Asp, editors]. London: Swedish Nutrition Foundation.

Hallberg L \& Rossander HL (1982) Effect of different drinks on the absorption of non-haem iron from composite meals. Hum Nutr Appl Nutr 36A 116-123.
Hallberg L, Rossander L \& Skanberg AB (1987) Phytates and the inhibitory effect of bran on iron absorption in man. Am J Clin Nutr 45, 988-996.

Hansen M, Bæch SB, Thomsen A, Tetens I \& Sandström B. (2005) Longterm intake of iron fortified whole-meal rye bread appears to benefit iron status of young women. J Cereal Sci, 42, 165-171.

Heath AL \& Fairweather-Tait SJ (2002) Clinical implications of changes in the modern diet: iron intake, absorption and status. Best Pract Res Clin Haematol 15, 225-241.

Huh EC, Hotchkiss A, Brouillette J \& Glahn RP (2004) Carbohydrate fractions from cooked fish promote iron uptake by Caco- 2 cells. $J$ Nutr 134, 1681-1689.

Hunt JR (2003) High, but not low bioavailability diets enable substantial control of women's iron absorption in relation to body iron stores, with minimal adaptation within several weeks. Am J Clin Nutr $\mathbf{7 8}$, $1168-1177$.

Hunt JR, Gallagher SK \& Johnson LK (1994) Effect of ascorbic acid on apparent iron absorption by women with low iron stores. Am J Clin Nutr 59, 1381-1385.

Hunt JR \& Roughead ZK (2000) Adaptation of iron absorption in men consuming diets with high or low iron bioavailability. Am J Clin Nutr 71, 94-102.

Hurrell R (2002) How to ensure adequate iron absorption from iron-fortified food. Nutr Rev 60, S7-15.

International Commission on Radiological Protection (1988) Radiation Dose to Patients from Radiopharmaceuticals. ICRP Publication no. 53. New York: Pergamon Press.

Layrisse M, Cook JD, Martinez C, Roche M, Kuhn IN, Walker RB \& Finch CA (1969) Food iron absorption: a comparison of vegetable and animal foods. Blood 33, 430-443.

Lynch SR (2000) The effect of calcium on iron absorption. Nutr Res Rev 13, $141-158$.

Martinez-Torres C \& Layrisse M (1971) Iron absorption from veal muscle. Am J Clin Nutr 24, 531-540.

Morck TA, Lynch SR \& Cook JD (1983) Inhibition of food iron absorption by coffee. Am J Clin Nutr 37, 416-420.

Reddy MB, Hurrell RF \& Cook JD (2000) Estimation of nonheme iron bioavailability from meal composition. Am J Clin Nutr 71, 937-943.

Samman S, Sandstrom B, Toft MB, Bukhare K, Jensen M, Sørensen SS \& Hansen M (2001) Green tea or rosemary extract added to foods reduces nonheme iron absorption. Am J Clin Nutr 73, 607-612.

Siegenberg D, Baynes RD, Bothwell TH, Macfarlane BJ, Lamparelli RD, Car NG, MacPhail P, Schmidt U, Tal A \& Mayet F (1991) Ascorbic acid prevents the dose-dependent inhibitory effects of polyphenols and phytates on nonheme iron absorption. Am J Clin Nutr 53, 537-541.

Skoglund E, Carlsson NG \& Sandberg AS (1998) High-performance chromatographic separation of inositol phosphate isomers on strong anion exchange columns. J Agric Food Chem 46, 1877-1882.

Taylor PG, Martinez TC, Romano EL \& Layrisse M (1986) The effect of cysteine-containing peptides released during meat digestion on iron absorption in humans. Am J Clin Nutr 43, 68-71.

Wienk KJ, Marx JJ \& Beynen AC (1999) The concept of iron bioavailability and its assessment. Eur J Nutr 38, 51-75. 